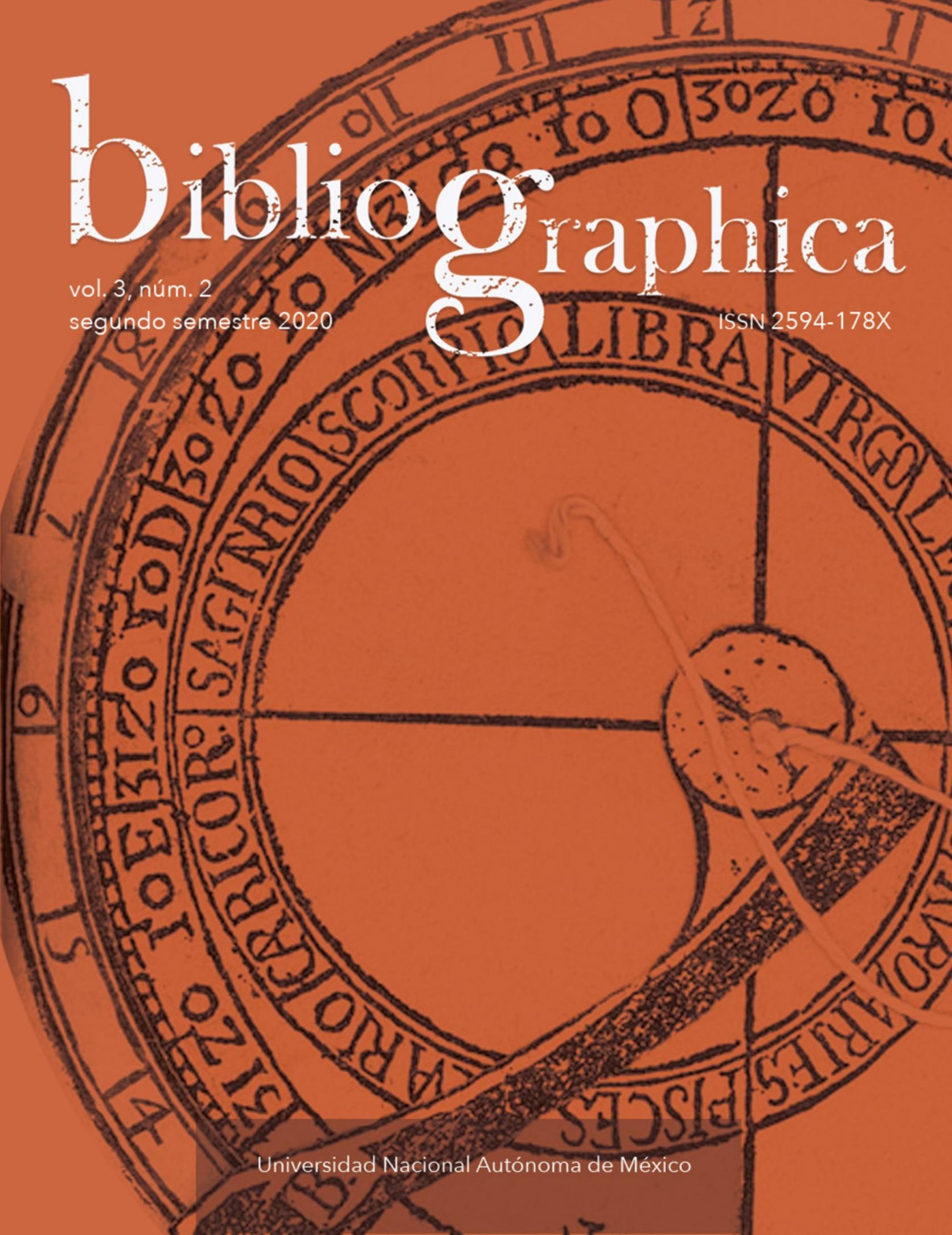




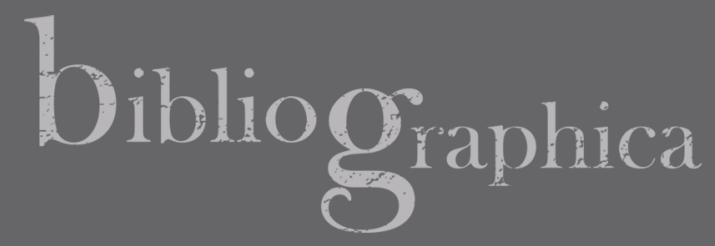

\section{Índice de nombres latinos de ciudades con imprenta, de José Ignacio Mantecón: una herramienta del pasado para el futuro}

Índice de nombres latinos de ciudades con imprenta, by José Ignacio Mantecón:

A Tool from the Past for the Future

\section{César Manrique Figueroa}

cesarmf@unam.mx

Universidad Nacional Autónoma de México

Instituto de Investigaciones Bibliográficas

Recepción: 15.05.2020 / Aceptación: 27.07.2020

DOI: https://doi.org/10.22201/iib.2594178xe.2020.2.85 
Resumen

En 1973 se inauguró la colección Instrumenta Bibliographica, publicada por el Instituto de Investigaciones Bibliográficas de la UNAM: el primer volumen fue el exitoso Manual de metodología y técnica bibliográficas de la profesora Gloria Escamilla González, que tuvo un par de ediciones aumentadas y reimpresiones; en segundo lugar apareció el Índice de nombres latinos de ciudades con imprenta 1448-1825, preparado por uno de los bibliógrafos más reconocidos en México durante el siglo XX, José Ignacio Mantecón Navasal. Este artículo subraya la relevancia, originalidad, vigencia y utilidad de esta obra pionera, poniéndola en contexto con la producción intelectual de Mantecón en México desde la década de 1940 y reflexionando sobre su beneficio y acerca de una posible modernización, corrección y edición digital de la misma.

Palabras clave

Abstract

Keywords
Bibliografía; historia del libro; libro antiguo; topónimos; Exilio español.

The collection Instrumenta Bibliographica was created by UNAM's Institute of Bibliographical Research in 1973. Its first volume was the successful Manual de metodología y técnica bibliográficas by Professor Gloria Escamilla González, which was reedited twice and subsequently reprinted. The following volume was the Índice de nombres latinos de ciudades con imprenta 1448-1825, prepared by one of the most widely recognized bibliographers of $20^{\text {th }}$ century Mexico, José Ignacio Mantecón Navasal. This paper underlines the relevance, originality, currency, and usefulness of this pioneering text, contextualizing it with Mantecon's work in Mexico from the 1940's onwards and, finally, eventualing a potential revision, correction, and digital reediting of Mantecon's Índice.

Bibliography; book history; ancient book; toponyms; Spanish exile. 


\section{Introducción}

A principios de la década de 1970, varios investigadores de la planta académica del relativamente joven Instituto de Investigaciones Bibliográficas de la UNAM (fundado en 1967), sucesor del Instituto Bibliográfico Mexicano, trabajaban en diversos proyectos institucionales y editoriales tanto de publicaciones periódicas como de colecciones. Por ejemplo la colección Instrumenta Bibliographica, en cuyo marco apareció el Índice de nombres latinos de ciudades con imprenta 1448-1825 de José Ignacio Mantecón Navasal, obra que me propongo analizar y mostrar como una herramienta vigente y de gran utilidad bibliográfica que, a casi 50 años de su publicación, merecería revisarse y actualizarse con el propósito de ofrecer un instrumento siempre útil para el estudio, identificación, descripción o catalogación del importante patrimonio bibliográfico del libro antiguo que custodiamos en los acervos nacionales del mundo de habla hispana.

\section{Los comienzos de la colección Instrumenta Bibliographica}

En 1973, el Instituto de Investigaciones Bibliográficas de la UNAM sacaba a la luz los dos primeros tomos de la colección Instrumenta Bibliographica, el primero de ellos, el Manual de metodología y técnica bibliográficas, ${ }^{2}$ corrió a cargo de la maestra Gloria Escamilla González (1926-2001), investigadora del propio instituto y jefa del Departamento de Catalogación de la Biblioteca Nacional de México. En esta concisa y práctica obra, la maestra Escamilla dejó constancia de su amplia experiencia en el campo de la llamada "bibliografía catalográfica", disciplina que cultivaba e impartía como una de las docentes más reconocidas del Colegio de Bibliotecología de la Facultad de Filosofía y Letras de la UNAM (establecido en 1956), en la materia de Métodos y técnicas de investigación bibliográfica. ${ }^{3}$

De hecho, el Manual fue bastante bien recibido, pues encontró entre los estudiantes y egresados de la carrera de Bibliotecología a un público de lectores asegurado, lo que se refleja en sus subsecuentes ediciones: la 2a. edición aumentada apareció solamente tres años después, en 1976, y la 3a. edición au-

\footnotetext{
1 José Ignacio Mantecón Navasal, Índice de nombres latinos de ciudades con imprenta 1448-1825 (México: UNAM, IIB, 1973).

2 Gloria Escamilla González, Manual de metodología y técnica bibliográficas (México: UNAM, IIB, 1973).

${ }^{3}$ Véase Felipe Meneses Tello, "La enseñanza de la bibliografía en México: el legado académico del Colegio de Biblioteconomía y Archivonomía", Bibliographica 1, núm. 1 (primer semestre de 2018): 140.
} 
mentada se publicó en 1982, reimpresa a su vez dos ocasiones más, en 1988 y 1997. ${ }^{4}$ En palabras de Felipe Meneses Tello: "Este libro ha sido, a través de los años, material fundamental de estudio en los cursos que sobre la materia han impartido otros profesores en el Colegio [de Bibliotecología de la FFyL] y seguramente en escuelas afines". ${ }^{5}$ En resumen, la colección Instrumenta Bibliographica se inauguraba con uno de los éxitos más notables del sello editorial del IIB, durante un periodo de casi 25 años.

El segundo volumen de dicha colección es el objeto de nuestras reflexiones en este artículo y corrió a cargo de un notable bibliógrafo en el ámbito hispanoamericano, el zaragozano José Ignacio Mantecón Navasal (1902-1982), colega -por cierto- de la maestra Escamilla, tanto en el IIB como en el Colegio de Bibliotecología de la Facultad. ${ }^{6}$ Se trata del Índice de nombres latinos de ciudades con imprenta 1448-1825 (1973), publicado en un tiraje de dos mil ejemplares.

\section{Algunos apuntes sobre la vida y obra de Mantecón}

Antes de hablar más a fondo sobre la estructura, relevancia y utilidad del Índice de nombres latinos de ciudades, vale la pena retomar un par de apuntes biográficos breves que nos recuerdan la sólida formación y amplia experiencia bibliográfica y archivística con las que contaba Mantecón al llegar a México. ${ }^{7}$ José

${ }^{4}$ Ibid., 162.

${ }^{5}$ lbid.

${ }^{6}$ Mantecón fue docente del Colegio de Bibliotecología desde 1963 hasta 1978, e impartió diferentes materias como Bibliología, Historia de las bibliotecas o Bibliotecología comparada, véase ibid., 168.

${ }^{7}$ Existen varios trabajos sobre la vida y producción intelectual de Mantecón, quizá los más detallados son aquellos elaborados por su nieto: Marco Aurelio Torres H. Mantecón, "Bibliografía general del doctor José Ignacio Mantecón Navasal", Boletín del Instituto de Investigaciones Bibliográficas 9, núms. 1 y 2 (primer y segundo semestres de 2004): 215279 y "Los maestros que perdimos los bibliotecarios: Semblanza de José Ignacio Mantecón Navasal", Educación y Bibliotecas, núm. 139 (2004): 74-81. También destacan: Irma Contreras García, "Homenaje semblanza del Dr. José Ignacio Mantecón Navasal", Anuario de Bibliotecología, época IV, núm. 3: 69-72; Silvia Salgado Ruelas, "Un bibliógrafo de ultramar: José Ignacio Mantecón", Escritos. Revista del Centro de Ciencias del Lenguaje, núm. 32 (julio-diciembre de 2005): 65-78; Aurora Sánchez Rebolledo, "José Ignacio Mantecón", en Enciclopedia de la Literatura en México ELEM, acceso el 28 de julio de 2020, http:// www.elem.mx/autor/datos/127999; Alejandro González Acosta, "José Ignacio Mantecón (1902-1982) un sabio de armas tomar", Boletín del Instituto de Investigaciones Bibliográficas 22, núms. 1 y 2 (primer y segundo semestre de 2017): 133-140; finalmente, en el 
Ignacio Mantecón Navasal nació en Zaragoza el 26 de septiembre de 1902, así que cuando llegó exiliado a Veracruz en julio de 1940 ya era un investigador y profesor experimentado, estudió simultáneamente Historia y Derecho en la Universidad de Zaragoza, se doctoró en Derecho por la Universidad Central de Madrid en 1924, el mismo año ingresó por oposición al Cuerpo Facultativo de Archiveros, Bibliotecarios y Arqueólogos de España, por lo cual trabajó los ricos fondos de la Biblioteca Nacional en Madrid y otros acervos documentales como el Archivo General de Indias, en donde permaneció tres años, entre 1926 y 1929. Asimismo, había participado activamente en el frente militar durante la Guerra Civil en el bando republicano, incluso fue nombrado gobernador general de Aragón; al término de la contienda y con la derrota republicana partió exiliado hacia Francia, estableciéndose definitivamente en México en $1940 .{ }^{8}$

Sería justamente en este país donde florecería su madurez intelectual, reflejada en su paso por diversas instituciones educativas mexicanas; primeramente, tuvo una etapa -entre 1943 y 1946-como becario-investigador en el recién fundado Colegio de México, en la época de don Alfonso Reyes (1889-1959), en donde desarrolló diversos trabajos, especialmente en colaboración con su amigo, colega y paisano Agustín Millares Carlo (1893-1980), de los cuales hablaremos más adelante. Su salida obedeció a la profunda crisis que atravesó esa institución durante el sexenio de Manuel Ávila Camacho (1940-1946), cuando fueron dados de baja varios académicos destacados, como Pedro Bosch Gimpera (1891-1974) o el propio Mantecón.?

En esa misma época fue profesor fundador y, eventualmente, emérito de la Escuela Nacional de Bibliotecarios y Archivistas desde su creación en 1945 hasta 1964, donde impartió materias como Paleografía, ciencia en la que tenía gran experiencia con archivos españoles y mexicanos, por ejemplo el de Protocolos Notariales de la Ciudad de México, de hecho, preparó junto con Millares Carlo los dos tomos del Índice y extractos de los Protocolos del Archivo de Notarías de México D. F. ${ }^{10}$

citado trabajo de Meneses Tello, una parte está dedicada al trabajo docente de Mantecón en el Colegio de Bibliotecología de la FFyL de la UNAM: Meneses Tello, "La enseñanza de la bibliografía...", 168-170.

8 Torres H. Mantecón, "Bibliografía general...", 216-217, González Acosta, "José Ignacio Mantecón...", 134-136.

9 Clara Lida, La Casa de España y El Colegio de México. Memoria 1938-2000 (México: El Colegio de México, 2000), 155, apud Salgado Ruelas, "Un bibliógrafo de ultramar...", 70.

${ }^{10}$ Agustín Millares Carlo y José Ignacio Mantecón, Índice y extractos de los Protocolos del Archivo de Notarías de México D. F, 2 vols. (México: El Colegio de México, Centro de 
Su carrera académica en la UNAM comenzó en el Instituto de Investigaciones Estéticas, al que ingresó en 1955 -año en que terminaba la dirección de su fundador Manuel Toussaint, a causa de su fallecimiento (1890-1955), y comenzaba la de Justino Fernández (1904-1972)-. De su paso por Estéticas destacan varias ediciones que corrieron a su cargo, como la Información de méritos y servicios de Alonso García Bravo, alarife que trazó la ciudad de México, texto preparado por José Ignacio Mantecón Navasal, con una introducción de Manuel Toussaint (1956); Pedro López de Villaseñor, Cartilla vieja de la nobilísima ciudad de Puebla (1781), edición e índices de Mantecón Navasal, con introducción de Efraín Castro (1961); o la Bibliografía de Manuel Toussaint, organizada y ampliada por Mantecón Navasal (1957). ${ }^{11}$

A partir de 1958 ingresó como investigador a la Biblioteca Nacional de México, institución adscrita a la UNAM, con sede entonces en el extemplo de San Agustín y que en esa época se encontraba sumida en una profunda crisis, pues estuvo cerrada al público. Su director era a la sazón Manuel Alcalá Anaya (19151999), quien contribuyó activamente para su reapertura oficial en 1963. ${ }^{12}$ De hecho, bajo la dirección de Alcalá, el Instituto Bibliográfico Mexicano fue restablecido en 1959 como una dependencia de la Biblioteca Nacional, ${ }^{13}$ y Mantecón Navasal fue miembro de su planta académica fundadora. Entre las tareas más relevantes del investigador - por la cantidad de trabajo que implicaba- estuvo la edición y preparación del Anuario Bibliográfico Mexicano 1958-1966, que recopilaba la producción editorial nacional de esos años y cuyos números aparecieron impresos después, entre 1967 y 1980 (es decir, el Anuario Bibliográfico correspondiente a 1958 se publicó en 1967, y así sucesivamente); ${ }^{14}$ asimismo,

Estudios Históricos, 1945-1946).

${ }^{11}$ Torres H. Mantecón, "Bibliografía general...", 223.

12 La obra de Manuel Alcalá al frente de la Biblioteca Nacional de México (1956 a 1965) destaca por haber promovido su reapertura oficial en 1963 y por incorporar una serie de notables académicos a sus filas de investigación, como los destacados Ignacio Osorio, Roberto Heredia, José Quiñones, Germán Viveros o el propio Mantecón. Véase: María Alejandra Valdés García, "Manuel Alcalá Anaya (1915-1999)", Boletín del Instituto de Investigaciones Bibliográficas 22, núms. 1 y 2 (primer y segundo semestre de 2017): 53-59.

${ }^{13}$ María del Carmen Ruiz Castañeda, "El Instituto Bibliográfico Mexicano, antecedente del Instituto de Investigaciones Bibliográficas. En su 30. Aniversario", Boletín del Instituto de Investigaciones Bibliográficas, nueva época, vol. II, núm. 2 (segundo semestre de 1997): 137. ${ }^{14}$ Según Ruiz Castañeda, por la falta de recursos durante la gestión del doctor Manuel Alcalá al frente de la Biblioteca Nacional, el Anuario Bibliográfico no salió a la imprenta en su momento sino posteriormente, ibid. 
se ocupó de la preparación del Boletín de la Biblioteca Nacional entre 1963 y 1967. ${ }^{15}$ Su libro más importante de este periodo fue probablemente el Índice de las traducciones impresas en México, que justamente apareció como un anejo al Boletín de la Biblioteca Nacional. ${ }^{16}$

Al crearse el Instituto de Investigaciones Bibliográficas de la UNAM (en agosto de 1967), Mantecón Navasal fue fundador de su planta académica, junto con un notable grupo de investigadores encabezados por don Ernesto de la Torre Villar (1917-2009), y jóvenes promesas como José Quiñones Melgoza (n. 1938). En Bibliográficas, el aragonés seguiría al frente de proyectos editoriales y de investigación vinculados con el Fondo de Origen de la Biblioteca Nacional, por ejemplo la dirección y edición -junto con Roberto Moreno de los Arcos (1943-1996) y Arturo Gómez Camacho (1936-2007)- de la publicación bimestral Bibliografía Mexicana de los años 1967-1978, sucesora del Anuario Bibliográfico; también fue miembro del consejo editorial del Boletín del Instituto de Investigaciones Bibliográficas entre 1969-1976, alternando con diferentes investigadores como María del Carmen Ruiz Castañeda (1926-2013), Roberto Moreno de los Arcos (1943-1996), Ignacio Osorio Romero (1941-1991), Gloria Escamilla González (1926-2001) o Jesús Yhmoff Cabrera (1932-1992).17

\section{El Índice de ciudades con imprenta}

Como investigador de Bibliográficas, Mantecón Navasal produjo dos libros, primeramente su Bibliografía general de don Justo Sierra, en colaboración con Irma Contreras e Ignacio Osorio (1969). Años después, en febrero de 1972, terminó de escribir la obra que más nos interesa en este artículo, el Índice de nombres latinos de ciudades con imprenta 1448-1825, dedicada afectuosamente a su "querido amigo y maestro Agustín Millares Carlo que tantas generaciones de humanistas, historiadores, bibliógrafos y bibliotecarios ha forjado en España e Hispanoamérica", ${ }^{18}$ quien en esa época se encontraba desarrollando su "incontenible pasión bibliográfica" en la Universidad de Zulia en Maracaibo, Venezuela, donde permaneció hasta 1974, antes de volver definitivamente a sus natales

\footnotetext{
${ }^{15}$ Torres H. Mantecón, "Bibliografía general...", 221.

${ }^{16}$ Mantecón Navasal, Índice de las traducciones impresas en México, 1959 (México: Biblioteca Nacional de México, Instituto Bibliográfico Mexicano, 1964).

17 Torres H. Mantecón, "Bibliografía general...", 221-222.

${ }^{18}$ Mantecón Navasal, Índice de nombres latinos de ciudades, 6.
} 
"ínsulas afortunadas", a decir del profesor José Pascual Buxó (1931-2019), es decir, el archipiélago canario. ${ }^{19}$

Vale la pena recordar que Millares Carlo fue otro brillante catedrático y bibliógrafo español transterrado a México a raíz de la Guerra Civil, y que su llegada, así como la de muchos otros académicos republicanos, enriqueció el ámbito de los estudios bibliográficos y bibliotecológicos en México, y el ambiente intelectual de la época, en general. Tanto Millares Carlo como Mantecón Navasal se conocieron en México por lo menos desde principios de la década de 1940, pues el primero se encontraba en el país a partir de 1938, fungiendo como vicecónsul al servicio de la República Española. ${ }^{20}$ Ambos habían trabajado juntos en varios proyectos en torno a estudios bibliográficos, paleográficos, históricos o de edición de textos entre 1940 y 1950; de hecho, inicialmente su trabajo fue el primer intento de recopilación histórica de la bibliografía mexicana, el utilísimo Ensayo de una bibliografía de bibliografías mexicanas (la imprenta, el libro, las bibliotecas), publicado en el marco de la II Feria del Libro y del Periodismo en México, por el entonces Departamento del Distrito Federal de 1943. También compartieron inquietudes literarias que se reflejan en su edición conjunta de La Celestina, introducción y notas de Agustín Millares Carlo y José Ignacio Mantecón (1947 por la editorial Leyenda), la cual fue actualizada y reeditada por la Dirección General de Publicaciones de la UNAM en 1964. ${ }^{21}$

De hecho, el interés de Mantecón Navasal por preparar una toponimia tipográfica en lengua española que sirviera como herramienta para bibliógrafos, bibliófilos e historiadores se remontaba por lo menos a los años 40, cuando sacó a la luz un pequeño artículo titulado: "Índice de los nombres latinos de ciudades utilizados en los pies de imprenta", el cual apareció en Letra y Pueblo. Boletín de la Biblioteca del H. Congreso de la Unión, 22 al parecer se trata de una publicación periódica poco conocida y de circulación limitada. Esta temprana contribución embrionaria de lo que sería su libro de 1973 no era para nada menor, pues no abundaban en nuestra lengua -y mucho menos publicados en

\footnotetext{
19 José Pascual Buxó, "Agustín Millares Carlo (1893-1980). El fervor de la sabiduría", Boletín del Instituto de Investigaciones Bibliográficas 22, núms. 1 y 2 (primer y segundo semestre de 2017): 141-146.

${ }^{20}$ González Acosta, "José Ignacio Mantecón...", 134-136.

${ }^{21}$ Torres H. Mantecón, "Bibliografía general...", 224-225.

22 Mantecón Navasal, "Índice de los nombres latinos de ciudades utilizados en los pies de imprenta", Letra y Pueblo. Boletín de la Biblioteca del H. Congreso de la Unión, segunda época, año 2, núm. 1 (enero-febrero de 1945): 53-80.
} 
México- estos estudios. En efecto, según afirma él mismo, el primer índice de este tipo que apareció en español fue el "Índice alfabético de las poblaciones en cuyas imprentas se han hecho impresiones notables", publicado en la Enciclopedia ilustrada universal europeo-americana en 1928,23 por lo cual su artículo de 1945 sería de los primeros índices de nombres de ciudades con imprenta publicados en español.

Ahora bien, a diferencia del tan solicitado manual de la profesora Escamilla, la UNAM no ha vuelto a reeditar, modernizar o ampliar el útil Índice de nombres latinos de ciudades con imprenta, a pesar de que contó con una gran difusión no sólo en México, sino que "ha sido enormemente utilizada en España, tanto por tratarse de una obra pionera como por su proximidad lingüística". ${ }^{24}$ De hecho, este tipo de índices o guías siguen siendo una herramienta fundamental y fácil de usar para cualquier persona vinculada desde diferentes disciplinas con el mundo del libro antiguo, pues, como su nombre lo indica, la obra provee una detallada lista de ciudades con imprenta y sus correspondientes nombres latinos, lo cual resulta clave para efectuar una correcta identificación, descripción y catalogación de materiales antiguos, así como su estudio.

\section{Estructura, relevancia y vigencia de la obra}

Este Índice de 1973 consta de una breve introducción en donde se destaca la metodología empleada, así como las principales fuentes y repertorios bibliográficos utilizados para su elaboración, que abarcan estudios clásicos de los siglos XVIII al XX. El trabajo introductorio de Mantecón Navasal fue tan completo en su época que sirvió de base para la Introducción del libro más reciente de Isabel Moyano, Toponomástica.

A continuación, el Índice ofrece la primera parte: "Nombres latinosnombres actuales", divida en dos columnas en donde se enlistan alfabéticamente, a la izquierda los nombres latinos de las ciudades, con la fecha aproximada de la llegada de la imprenta a cada una de ellas, según la información disponible en la época, y los nombres actuales a la derecha, con el nombre del país al que pertenecen -o pertenecían, en aquel ya lejano 1973- puesto entre

23 "Índice alfabético de las poblaciones en cuyas imprentas se han hecho impresiones notables", en Enciclopedia ilustrada universal europeo-americana, vol. 61 (Barcelona; Madrid: Espasa-Calpe, 1928), 1539-1543.

${ }^{24}$ Isabel Moyano Andrés, Toponomástica. Instrumenta Bibliológica (Madrid: Arco / Libros, 2006), 9. 
paréntesis. La lista comienza con AALBURGIUM = Aalborg (Dinamarca) y finaliza con ZWOLLAE = Zwolle (Países Bajos).

En la segunda parte, "Nombres actuales-nombres latinos", se invierte el orden de búsqueda, pues se colocan alfabéticamente a la izquierda los nombres actuales y a la derecha las versiones latinas, comenzando con la antigua ciudad alemana de AACHEN (Aquisgrán en español) y sus variantes latinas Aquae Grani, Aquisgranum, y finalizando con ZWOLLE (Países Bajos) - Zwollae.

La obra termina con una pequeña addenda de algunas ciudades que faltaron, como ALCANITIUM - Alcañiz (España), y que seguramente ya no fue posible incluir en el manuscrito que se fue a imprenta.

Este tipo de obras tiene un propósito fundamental, para asistir a un público no latinista en la certera identificación de las publicaciones estudiadas, pues no siempre resulta evidente o sencilla la identificación de nombres latinos, que en ocasiones son verdaderamente crípticos para quien no los conoce. El propio Mantecón Navasal -un erudito y conocedor de los fondos de la Biblioteca Nacional de España, y luego en la de México- decía que: "Por propia experiencia sé que supone, casi siempre, una penosa tarea para bibliotecarios, bibliógrafos e incluso historiadores, identificar los nombres actuales de tales lugares". ${ }^{25}$

Ofrezco algunos ejemplos prácticos con los que se topan todos los interesados en el mundo del libro antiguo, en particular aquel impreso abundantemente en latín, la lengua culta de la época entre el siglo XV y hasta bien entrado el último tercio del XVIII, es decir, prácticamente todo el periodo que comprende la imprenta manual.

El caso de la ciudad de Madrid nos resulta ilustrativo, en algunas ocasiones sus impresos en latín llevan el pie de imprenta de Madritum o Matritum, formas latinas que no nos parecen tan alejadas de su nombre en español, sin embargo, existen otras variantes que pueden crear confusión, por ejemplo: Mantua Carpetanorum, nombre que a primera vista podría remitirnos a la ciudad natal de Virgilio, la bella Mantua en la Lombardía italiana, sin embargo, al consultar el Índice de Mantecón Navasal nos damos cuenta de que no se trata de la ciudad italiana, sino de la mismísima Madrid. Incluso existe otra variante para la capital española: Colonia Viriata, nombre que, sin saberlo, podría asociarse con la ciudad alemana de Colonia a orillas del Rin. Ya decía Mantecón al respecto que "Madrid de humildísimo origen, se le disfrazó como Mantua Carpetanorum o Viriathica". 26

\footnotetext{
${ }^{25}$ Mantecón Navasal, Índice de nombres latinos de ciudades, 9.

${ }^{26}$ Ibid., 10.
} 
Otro caso interesante lo ofrece la capital francesa, París, definitivamente uno de los centros tipográficos de mayor envergadura en cuanto a su producción entre los siglos XVI al XVIII, y de cuyos impresos en latín están llenos los fondos históricos en América Latina. El nombre de París puede ser latinizado de varias formas no tan alejadas de la actual: Parigi, Parisis, Parisius, sin embargo, otras variantes se desprenden del antiguo nombre que dieron los romanos al asentamiento fundado en la Isla de la Cité: Lutecia, Lutetia, Lutetiae Parisiorum, por lo que aquellos no familiarizados o versados en historia romana no tendrían por qué saber que Lutecia refiere al nombre galo-romano de París.

La cosa se complica cuando los impresores de innumerables ciudades crearon nombres "ilustres" en (neo)latín, no siempre correctamente declinados, buscando vincular sus localidades con un glorioso pasado romano, muchas veces imaginado e inexistente, o en palabras de Mantecón: "muchas formas de los nombres latinos son debidas a caprichos de aprendices de latinistas, a rebuscadas analogías fonéticas, atribuciones históricas fabulosas [...] o un excesivo amor a la patria chica de algunos autores que quisieron dar, con veste latina, antigüedad a sus patrios lares". ${ }^{27}$

Estos rimbombantes nombres en latín también desorientaban a los lectores de la época, por ejemplo, los nombres latinos de la ciudad suiza de Ginebra son Aurelia Allobrogum o Colonia Allobrogum. Como bien lo apuntaban Cristina Gómez Álvarez y Laurence Coudart, este tipo de nombres latinizados podían despistar a los censores de libros o a los encargados de hacer inventarios en la Nueva España o, en general, en los territorios de la monarquía hispánica durante la Edad Moderna, pues el nombre podría ser asociado con el de una ciudad católica como Colonia y no con una abiertamente protestante como lo era Ginebra desde el siglo XVI: "Las direcciones extravagantes, con frecuencia traducciones del nombre en latín o del de la antigua colonia romana, permiten al editor escapar de las persecuciones y al libro cruzar las fronteras y venderse". 28

Los mismos libreros impresores de Ginebra o Lausana en el XVIII sabían que al usar el nombre Colonia Allobrogum sus libros destinados al mercado hispánico serían recibidos sin problemas, así lo expresaba en una misiva de 1754 el librero suizo François Grasset (ca. 1722-1789): "Nuestras casas de Ginebra y Lausana ponen siempre al pie de las portadas Coloniae Allobrogum, porque

\footnotetext{
${ }^{27}$ Ibid., 9.

${ }^{28}$ Laurence Coudart y Cristina Gómez Álvarez, "Las bibliotecas particulares del siglo XVIII: una fuente para el historiador", Secuencia. Revista de Historia y Ciencias Sociales, núm. 56 (mayo de 2003): 183.
} 
sin esas palabras aunque el libro fuese bueno, seguramente no se vendería en España con la palabra Ginebra o Lausana por el gran prejuicio español". ${ }^{29}$

Otro de los factores a considerar en el estudio de impresos antiguos es la omnipresente variación en la ortografía onomástica de los nombres en latín, por lo que hay que buscar meticulosamente en los catálogos de bibliotecas con fondos históricos, cuando se está buscando por ciudad de impresión. Pongo como ejemplo el caso de la ciudad de Amberes, pues el nombre del gran puerto de la actual Bélgica puede figurar en latín en al menos cuatro variantes más utilizadas: Antverpiae, Antuerpiae, Antvuerpia, Antuerpia. Asimismo, el nombre de Amberes en lenguas vernáculas modernas también cambia bastante entre una y otra (a diferencia del nombre de ciudades como Roma o Madrid, que permanecen más estables), de tal manera que en las obras impresas en español en dicha ciudad puede figurar el nombre de: "Amberes" tal y como lo usamos ahora, o "Enveres" (así aparece en impresos en español del siglo XVI), sin olvidar otras variantes: Anvers (francés), Antuérpia (portugués), Anversa (italiano), Antwerp (inglés) o Antwerpen (neerlandés y alemán), por lo cual -además de las variantes de escritura en los nombres latinos- no hay que perder de vista las variaciones gráficas entre las lenguas modernas. Un ejemplo similar lo ofrece otra ciudad de la actual Bélgica: Lieja, Liège (en francés, variante que también se usa en inglés), Luik (neerlandés), Lüttich (alemán) y Augusta Eboronum, Leodicum, Leudicum, Leodium, entre otros nombres en latín.

\section{Hacia una moderna reedición digital}

Como ya se dijo, el Índice de Mantecón Navasal fue uno de los trabajos que sirvió como inspiración y punto de partida para la obra más reciente de Isabel Moyano Andrés, Toponomástica (2006), la cual se publicó como parte de la colección Instrumenta Bibliológica, coordinada por Julián Martín Abad. Moyano sigue prácticamente el esquema utilizado por Mantecón, ${ }^{30}$ a saber: Introducción, una primera parte con los nombres latinos ordenados alfabéticamente en la columna de la izquierda, mientras que a la derecha se colocan los nombres

\footnotetext{
${ }^{29}$ Citado en Coudart y Gómez Álvarez, ibid.

${ }^{30}$ Llama la atención que en la bibliografía del libro de Isabel Moyano, el registro de Mantecón Navasal presenta varios errores: pone como nombre de pila Juan Ignacio por José Ignacio, pero lo que más destaca es la referencia a que el libro fue publicado por el Fondo de Cultura Económica en 1972, y no por el Instituto de Investigaciones Bibliográficas de la UNAM en 1973.
} 
modernos de las ciudades y el país al que pertenecen actualmente entre paréntesis; una segunda parte enlista los nombres actuales de las ciudades a la izquierda, y a la derecha ofrece sus nombres latinos y sus variantes. Este esfuerzo de Moyano demuestra la vigencia que tiene este tipo de herramientas de consulta como apoyo para los bibliotecarios, bibliógrafos o estudiosos del libro y de la imprenta. Cabe señalar que en su tiempo Mantecón Navasal utilizaba el término toponimia, pero Moyano retoma para su propia obra el término del libro italiano de Tomaso Urso, Toponomastica bibliografica: guida ai nomi dei luoghi di stampa fino al 1799. ${ }^{31}$

Debido a todas estas consideraciones, por su utilidad como herramienta para los estudios del libro antiguo, la vigencia permanente del Índice de Mantecón Navasal y por la dificultad de conseguir el libro de Isabel Moyano en México, es factible pensar en una reedición digital inspirada en Mantecón, ciertamente, tras una necesaria revisión, corrección de erratas y modernización del texto, pues, en primer lugar, el contexto geopolítico de nuestro siempre cambiante planeta no es el mismo que en 1973, por lo cual diversas ciudades - particularmente las del bloque socialista de Europa oriental-se mencionan en naciones que ya no existen en el mapamundi, tal es el caso de Praga, capital de la entonces Checoslovaquia (dividida en República Checa y Eslovaquia); Belgrado, Zagreb o Liubliana son mencionadas en 1973 como parte de Yugoslavia (actualmente son las capitales de las respectivas repúblicas de Serbia, Croacia y Eslovenia); o Kiev, Tallin y Moscú, que se mencionan todas como parte de la antigua URSS (y que ahora corresponden a las capitales de Ucrania, Estonia y la Federación Rusa, respectivamente).

Alguna otra ciudad ha mudado su nombre ante los cambios de régimen, el ejemplo por excelencia lo brinda San Petersburgo, que Mantecón Navasal todavía registra con su nombre de la era soviética: Leningrado. El propio Mantecón advertía sobre los cambios geopolíticos tras las guerras mundiales, el caso que cita es el de la ciudad prusiana de Koenigsberg, que al pasar a manos soviéticas cambió su nombre alemán al de Kaliningrado. ${ }^{32}$

Otro aspecto para corregir son las erratas -correctamente señaladas por Isabel Moyano-, de las cuales el texto de Mantecón Navasal no está exento, en particular las fechas de introducción de la imprenta que, como sabemos, han

\footnotetext{
${ }^{31}$ Tomaso Urso, Toponomastica bibliografica: guida ai nomi dei luoghi di stampa fino al 1799 (Florencia: Leo. S. Olschki Editore, 1990).

32 Mantecón Navasal, Índice de nombres latinos de ciudades, 9.
} 
variado gracias a los hallazgos documentales acumulados durante más de 40 años de investigación sobre la historia de la imprenta de las ciudades. Un caso curioso es el de Segovia, pionera en la península ibérica, pues Mantecón señala que la imprenta llegó ahí hasta 1525, aunque en su época ya se sabía que su llegada a esa ciudad databa de 1472 -me parece, por cierto, muy raro que Moyano señale este error en Mantecón, pero lo repita ella misma en su lista de ciudades-. ${ }^{33}$ Otro error señalado, al parecer bastante conocido, es el nombre en latín de la ciudad de Sigüenza, que Mantecón consigna erróneamente como Seguntia apud Lequericam y que mezcla el nombre latino Seguntia con apud Lequericam, lo cual "es simplemente el nombre del impresor Juan Iñiguez de Lequerica, que por cierto no imprimió nada en Sigüenza". ${ }^{34}$

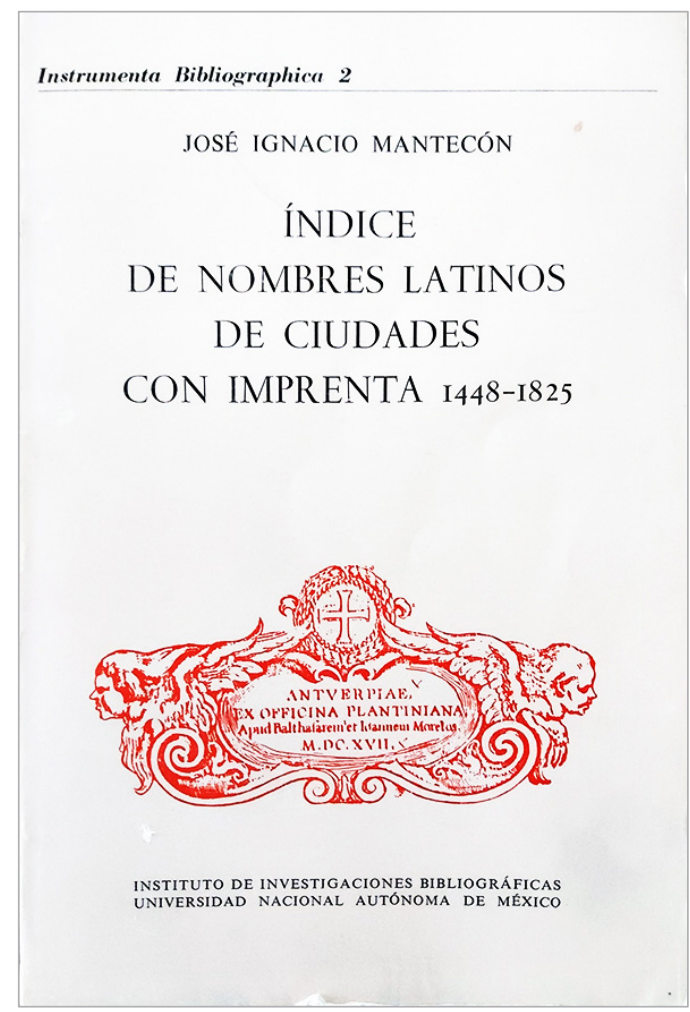

${ }_{33}^{33}$ Moyano Andrés, Toponomástica, 9-10, 157.

${ }^{34}$ Ibid., 10. 
Una moderna y revisada reedición digital del Índice de José Ignacio Mantecón podría encontrar cabida en la nueva serie Instrumenta Bibliographica que prepara la Biblioteca Nacional de México, disponible como una herramienta abierta para consultas rápidas, respetando la estructura del texto original, pero con una necesaria actualización de sus entradas. Dicha publicación en soporte digital sería de gran utilidad para los catalogadores o estudiosos de fondos antiguos en nuestro país y, en general, en el mundo de habla hispana, particularmente entre los estudiantes más jóvenes que no estén familiarizados -por la poca accesibilidad a las obras de Mantecón o de Moyano-, la primera porque su tiraje está agotado y la segunda porque no siempre resulta tarea sencilla conseguir libros españoles en el mercado mexicano o latinoamericano.
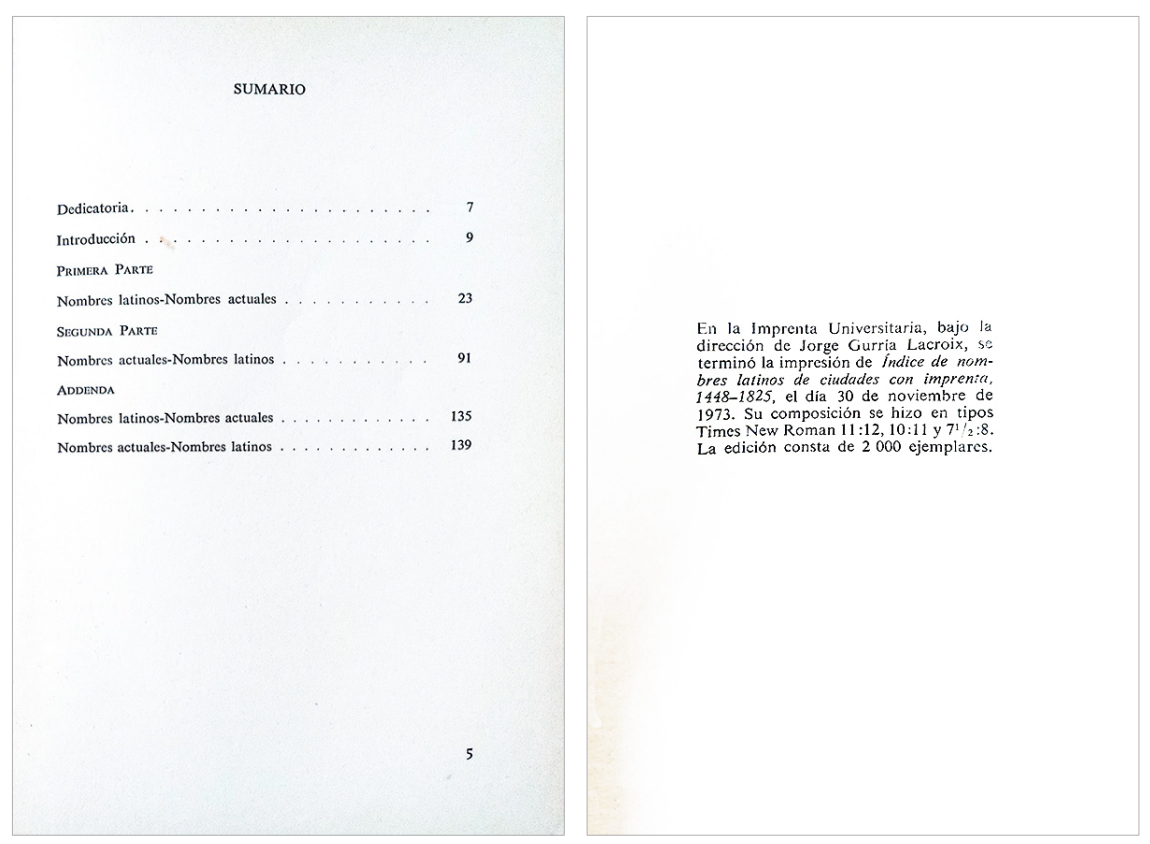


\section{Conclusiones. La permanente utilidad del Índice de Mantecón}

En años recientes se ha visto en México una proliferación de estudios e interés en torno al libro antiguo, desde diferentes disciplinas, enfoques, instituciones y en diversos fondos históricos del país. Personalmente, me ha interesado el estudio de la producción, comercio y circulación en la Nueva España de libros impresos en la región geográfica e histórica conocida como los Países Bajos, específicamente en los llamados Estados de Flandes o Países Bajos meridionales. Por tanto, puedo afirmar que durante estos años he adquirido cierta familiaridad con los nombres latinos utilizados por los impresores y por las ciudades con imprenta, tanto de Flandes como de los actuales Países Bajos, durante los siglos XVI y XVII. Sin embargo, a pesar de este conocimiento en torno a nombres latinos de ciudades europeas, me gustaría retomar una anécdota verídica y bastante reciente que, a mi parecer, ocurre frecuentemente en los ámbitos de estudio del libro antiguo.

Al revisar catálogos bibliográficos internacionales de libros impresos en el siglo XVI, me topé con el nombre de Daventria como lugar de impresión, y traté en vano de recordar de qué ciudad se trataba. Ante tal situación, el investigador, bibliógrafo, estudioso o interesado en general tiene que recurrir "forzosamente" a un instrumento de consulta rápida fundamental en estos menesteres, me refiero naturalmente a un Índice como el de Mantecón. Evidentemente, su consulta me aclaró que Daventria se trata de la actual ciudad holandesa de Deventer, importante centro -por cierto- de uno de los movimientos religiosos más significativos de la Baja Edad Media, la devotio moderna. ${ }^{35}$

El caso es que -incluso para estudiosos o catalogadores ciertamente familiarizados con los nombres latinos de los centros tipográficos europeos- la obra de José Ignacio Mantecón sigue siendo una herramienta de gran utilidad para la catalogación, estudio o investigación del libro antiguo impreso en latín, tan abundante en los fondos históricos mexicanos, y también para los bibliófilos o coleccionistas. Por ello, he decidido escribir este texto, para destacar una vigencia innegable y hacer énfasis en la necesidad de una actualización en formato digital de una obra preparada por un hombre considerado un pilar fundacional dentro de los estudios bibliográficos del siglo XX en México.

\footnotetext{
${ }_{35}^{35}$ Deventer está ubicada en la provincia de Overijssel, en los Países Bajos, ahí surgieron los Hermanos de la Vida Común, importantes agentes en el desarrollo de la devotio moderna durante el siglo XIV.
} 


\section{Referencias}

Blasco Gil, Yolanda. "Millares Carlo en el exilio". Cuestiones Pedagógicas 20 (2009-2010): 161-179. Acceso el 31 de julio de 2020. http://institucional. us.es/revistas/cuestiones/20/art_08.pdf.

Contreras García, Irma. "Homenaje semblanza del Dr. José Ignacio Mantecón Navasal". Anuario de Bibliotecología, época IV, núm. 3: 69-72.

Coudart, Laurence y Cristina Gómez Álvarez. "Las bibliotecas particulares del siglo XVIII: una fuente para el historiador". Secuencia. Revista de Historia y Ciencias Sociales, núm. 56 (mayo de 2003): 173-191.

Escamilla González, Gloria. Manual de metodología y técnica bibliográficas. Instrumenta Bibliographica 1. México: Universidad Nacional Autónoma de México, Instituto de Investigaciones Bibliográficas, 1973.

González Acosta, Alejandro. "José Ignacio Mantecón (1902-1982) un sabio de armas tomar". Boletín del Instituto de Investigaciones Bibliográficas 22, núms. 1 y 2 (primer y segundo semestre de 2017): 133-140.

"Índice alfabético de las poblaciones en cuyas imprentas se han hecho impresiones notables". En Enciclopedia ilustrada universal europeo-americana. Vol. 61, 1539-1543. Barcelona; Madrid: Espasa-Calpe, 1928.

Lida, Clara. La Casa de España y El Colegio de México. Memoria 1938-2000. México: El Colegio de México, 2000.

Mantecón Navasal, José Ignacio. Índice de las traducciones impresas en México, 1959. México: Biblioteca Nacional de México, Instituto Bibliográfico Mexicano, 1964.

Mantecón Navasal, José Ignacio. Índice de nombres latinos de ciudades con imprenta 1448-1825. Instrumenta Bibliographica 2. México: Universidad Nacional Autónoma de México, Instituto de Investigaciones Bibliográficas, 1973.

Mantecón Navasal, José Ignacio. "Índice de los nombres latinos de ciudades utilizados en los pies de imprenta". Letra y Pueblo. Boletín de la Biblioteca del H. Congreso de la Unión, segunda época, año 2, núm. 1 (enero-febrero de 1945): 53-80.

Meneses Tello, Felipe. "La enseñanza de la bibliografía en México: el legado académico del Colegio de Biblioteconomía y Archivonomía". Bibliographica 1, núm. 1 (primer semestre de 2018): 116-180. 
Millares Carlo, Agustín y José Ignacio Mantecón. Índice y extractos de los Protocolos del Archivo de Notarías de México, D. F. 2 vols. México: El Colegio de México, Centro de Estudios Históricos, 1945-1946.

Morales Campos, Estela. "José Ignacio Mantecón (1909-1982)". En Estudios y testimonios sobre el exilio español el México. Una visión sobre su presencia en las humanidades. Coordinación de Armando Pavón Romero, Clara Inés Ramírez González y Ambrosio Velasco Gómez. Pública Memoria 4, 393-399. México: Bonilla-Artigas Editores / Conacyt, 2016. Acceso el 31 de julio de 2020. https://www.worldcat.org/title/estudios-y-testimonios-so bre-el-exilio-espanol-en-mexico-una-vision-sobre-su-presencia-en-las-hu manidades/oclc/1001294119.

Moyano Andrés, Isabel. Toponomástica. Instrumenta Bibliológica. Madrid: Arco / Libros, 2006.

Pascual Buxó, José. "Agustín Millares Carlo (1893-1980). El fervor de la sabiduría". Boletín del Instituto de Investigaciones Bibliográficas 22, núms. 1 y 2 (primer y segundo semestre de 2017): 141-146.

Ruiz Castañeda, María del Carmen. "El Instituto Bibliográfico Mexicano, antecedente del Instituto de Investigaciones Bibliográficas. En su $30^{\circ}$. Aniversario". Boletín del Instituto de Investigaciones Bibliográficas, nueva época, vol. II, núm. 2 (segundo semestre de 1997): 129-143.

Salgado Ruelas, Silvia. "Un bibliógrafo de ultramar: José Ignacio Mantecón". Escritos. Revista del Centro de Ciencias del Lenguaje, núm. 32 (juliodiciembre de 2005): 65-78.

Sánchez Rebolledo, Aurora. "José Ignacio Mantecón". En Enciclopedia de la Literatura en México ELEM. Acceso el 28 de julio de 2020. http://www.elem. $\mathrm{mx} /$ autor/datos/127999.

Torres H. Mantecón, Marco Aurelio. “Bibliografía general del doctor José Ignacio Mantecón Navasal". Boletín del Instituto de Investigaciones Bibliográficas 9, núms. 1 y 2 (primer y segundo semestres de 2004): 215-279.

Torres H. Mantecón, Marco Aurelio. "Los maestros que perdimos los bibliotecarios: Semblanza de José Ignacio Mantecón Navasal". Educación y Bibliotecas, núm. 139 (2004): 74-81.

Urso Tomaso. Toponomastica bibliografica: guida ai nomi dei luoghi di stampa fino al 1799. Florencia: Leo. S. Olschki Editore, 1990.

Valdés García, María Alejandra. "Manuel Alcalá Anaya (1915-1999)". Boletín del Instituto de Investigaciones Bibliográficas 22 núms. 1 y 2 (primer y segundo semestre de 2017): 53-59. bg 